\title{
Increased phosphorylation of eIF2a in chronic myeloid leukemia cells stimulates secretion of matrix modifying enzymes
}

\author{
Paulina Podszywalow-Bartnicka ${ }^{1}$, Anna Cmoch², Magdalena Wolczyk ${ }^{1}$, Lukasz \\ Bugajski ${ }^{1}$, Marta Tkaczyk ${ }^{3}$, Michal Dadlez ${ }^{3}$, Margaret Nieborowska-Skorska ${ }^{4}$, \\ Antonis E. Koromilas ${ }^{5,6}$, Tomasz Skorski ${ }^{4}$, Katarzyna Piwocka ${ }^{1}$ \\ ${ }^{1}$ Laboratory of Cytometry, Nencki Institute of Experimental Biology of Polish Academy of Sciences, Warsaw, Poland \\ ${ }^{2}$ Laboratory of Lipid Biochemistry, Department of Biochemistry, Nencki Institute of Experimental Biology of Polish Academy \\ of Sciences, Warsaw, Poland \\ ${ }^{3}$ Laboratory of Mass Spectrometry, Institute of Biochemistry and Biophysics, Polish Academy of Sciences, Warsaw, Poland \\ ${ }^{4}$ Department of Microbiology and Immunology, Temple University School of Medicine, Philadelphia, USA \\ ${ }^{5}$ Lady Davis Institute for Medical Research, McGill University, Sir Mortimer B. Davis-Jewish General Hospital, Montreal, \\ Quebec, Canada \\ ${ }^{6}$ Department of Oncology, Faculty of Medicine, McGill University, Montreal, Quebec, Canada \\ Correspondence to: Katarzyna Piwocka, email: k.piwocka@nencki.gov.pl \\ Keywords: CML, elF2a, ATF4, proteases, cell invasion \\ Received: April 13,2016 Accepted: October 17, $2016 \quad$ Published: October 27, 2016
}

\section{ABSTRACT}

Recent studies underscore the role of the microenvironment in therapy resistance of chronic myeloid leukemia (CML) cells and leukemia progression. We previously showed that sustained mild activation of endoplasmic reticulum (ER) stress in CML cells supports their survival and resistance to chemotherapy. We now demonstrate, using dominant negative non-phosphorylable mutant of eukaryotic initiation factor 2 a subunit (eIF2a), that phosphorylation of eIF2a (eIF2a-P), which is a hallmark of ER stress in CML cells, substantially enhances their invasive potential and modifies their ability to secrete extracellular components, including the matrix-modifying enzymes cathepsins and matrix metalloproteinases. These changes are dependent on the induction of activating transcription factor-4 (ATF4) and facilitate extracellular matrix degradation by CML cells. Conditioned media from CML cells with constitutive activation of the eIF2a-P/ATF4 pathway induces invasiveness of bone marrow stromal fibroblasts, suggesting that eIF2a-P may be important for extracellular matrix remodeling and thus leukemia cells-stroma interactions. Our data show that activation of stress response in CML cells may contribute to the disruption of bone marrow niche components by cancer cells and in this way support CML progression.

\section{INTRODUCTION}

The bone marrow microenvironment creates a unique niche, which is essential for hematopoiesis, but also supports the development of leukemia. Bone marrow stromal fibroblasts support the proliferation of leukemia cells [1] and their resistance to therapy [2]. Cytokines secreted by stromal cells, induce homing and keep cells in a quiescent state [3], which in case of chronic myeloid leukemia (CML), remain particularly resistant to most of available chemotherapeutics $[4,5]$ and are responsible for cancer relapse. Additionally, development of leukemia disturbs the cellular composition of bone marrow [6]. Modification of the extracellular milieu by cytokines secreted by leukemia cells evokes phenotypic changes in surrounding cells that leads to impairment of hematopoiesis [7] and stimulation of angiogenesis [8-12]. Accumulation of highly proliferating cells results in insufficient oxygen and nutrients supplementation and upsets the balance of growth factors. Leukemia cells secrete matrix metalloproteinases (MMPs), which degrade extracellular matrix (ECM) and by this destroy non-cellular components of the niche [13-18] and modify composition of signaling molecules. Altogether it leads to transformation of the bone marrow niche that supports leukemia progression.

Glucose starvation or hypoxia trigger endoplasmic reticulum (ER) stress that activates unfolded protein response 
(UPR). UPR induces three major stress sensors located within the ER: Ser/Thr protein kinase with endonuclease activity (IRE1), activating transcription factor-6 (ATF6) and protein kinase R-like endoplasmic reticulum kinase (PERK) (reviewed in [19]). One of the main substrates of PERK is Ser 51 of eukaryotic initiation factor $2 \alpha$ subunit (eIF2 $\alpha$ ). Phosphorylation of eIF $2 \alpha$ inhibits the formation of a ternary complex responsible for initiation of mRNA translation. As a result, translation of most mRNAs is selectively blocked in favor of synthesis of proteins necessary for cell adaptation to stressful conditions. Some proteins are synthesized exclusively upon eIF2 $\alpha$ phosphorylation, such as activating transcription factor 4 (ATF4) [20]. The ultimate effect of the UPR activation depends on the severity of the stress stimulus. Upon severe stress, activation of the UPR pathway eventually leads to apoptosis. On the other hand, mild or transient stress results in the adjustment of the cellular protein profile to support cell adaptation and survival.

Induction of mild ER stress was initially observed in cells that form solid tumors. We found that ER stress is also triggered in CML, a non-solid cancer type [21], and evokes sustained activation of UPR and increased phosphorylation of eIF $2 \alpha$ (eIF2 $\alpha-\mathrm{P})$ in CML cells [22]. Activity of this pathway correlated with leukemia progression and therapy resistance $[22,23]$ and increase of eIF $2 \alpha-\mathrm{P}$ in primary Lin-CD34+ cells accompanied CML progression and enhanced their leukemogenic potential [22]. Recent studies confirmed the pro-survival role of eIF $2 \alpha$ phosphorylation in leukemia cells upon energetic stress [24]. In parallel, the protective role of eIF2 $\alpha$ phosphorylation and ATF4 synthesis in other types of cancers has been recently described [25-28].

Despite the important role that eIF $2 \alpha-\mathrm{P}$ plays in CML progression, its function in the regulation of the microenvironment of leukemia cells has remained unclear. Here, we show that eIF $2 \alpha-\mathrm{P}$ affects the composition of proteins secreted by leukemia cells, including enzymes that degrade the extracellular matrix, such as matrix metalloproteinases (MMPs) and cathepsins. We further show that enhanced phosphorylation of eIF2 $\alpha$ supports the invasiveness of leukemia cells in a manner dependent on the ATF4 transcription factor. Proteins secreted by CML cells in response to the activation of the eIF $2 \alpha-\mathrm{P} / \mathrm{ATF} 4$ axis increase the invasiveness of human bone marrow stromal fibroblasts. Our findings reveal a key novel function of eIF $2 \alpha-\mathrm{P}$ in the regulation of the interaction between CML cells and tumor stroma in response to stress and point to ATF4 as a potent therapeutic target.

\section{RESULTS}

\section{Phosphorylation of eIF2 $\alpha$ in $\mathrm{K562}$ cells regulates secretion of extracellular enzymes}

We previously demonstrated correlation between CML progression and increased eIF2 $\alpha-\mathrm{P}$ [22]. We hypothesized that in addition to its direct effects on CML cells, eIF2 $\alpha$-P might affect the microenvironment of CML through secreted proteins. In order to study the effect of eIF $2 \alpha-\mathrm{P}$ on the composition of CML secretome, we performed quantitative proteomics on media conditioned by K562 CML cells expressing GFP (K562wt) or a nonphosphorylable mutant of eIF2 $\alpha$ (K562mut), which acts as a dominant negative protein and prevents the phosphorylation of endogenous eIF $2 \alpha$ [22]. Decrease in eIF $2 \alpha$ phosphorylation in total cell lysates of K562mut cells was confirmed by immunoblot (Figure 1A).

In order to quantitatively determine changes in secreted proteins between K562wt and K562mut cells, we used stable isotope labelling by amino acids in cell culture coupled with liquid chromatography-tandem mass spectrometry (SILAC LC-MS/MS) and compared proteins of soluble components from media conditioned by either cell line. To this end, the conditioned media (S) from K562wt (K562wt_S) and K562mut (K562mut_S) cell cultures was cleared of membrane fragments and extracellular vesicles by multistep ultracentrifugation. In total, we identified 2528 proteins using Mascot by at least 2 peptides with a false recovery rate (FDR) of 0.01 . Among these, the level of 101 proteins was significantly different between the two conditions. In this group, 83 proteins were decreased and 18 were enriched in media conditioned by K562mut compared to K562wt cells (Figure 1B). Gene Ontology analysis revealed that $52 \%$ of proteins, whose concentration was reduced upon decline of eIF $2 \alpha$ phosphorylation, possessed catalytic activity (Figure 1C, Table S1) The most abundant enzymes in this group were those involved in the degradation of components of the extracellular matrix (ECM). Apart from ECM-degrading enzymes, there was a significant group of proteins binding to collagen (2\%), lipids (5\%) and other extracellular matrix components $(3 \%)$ in a noncatalytic manner. The decrease in the release of enzymes by K562mut cells was further confirmed using antibody arrays (Figure 1D; representative blots are shown in Supplementary Figure S1).

We then used the Search Tool for the Retrieval of Interacting Genes/Proteins (STRING) database to determine if enzymes secreted selectively by K562wt but not K562mut cells interacted physically with one another or were functionally associated. Application of the MCL clustering algorithm yielded two interacting groups - one containing enzymes with MMP activity and another with cathepsin (CTS)-related enzymes (Figure 1E).

We selected CTSs and MMPs for further studies. Apart from MMP-9, the involvement of these proteases in leukemia progression had not been investigated. To determine if the observed changes in CTS and MMP secretion could be attributed to changes at the level of transcription, we measured mRNA levels of selected enzymes by quantitative RT-PCR (Figure 1F). In K562mut cells the level of CTSA, CTSB, CTSS and MMP-9 mRNA 
(A)

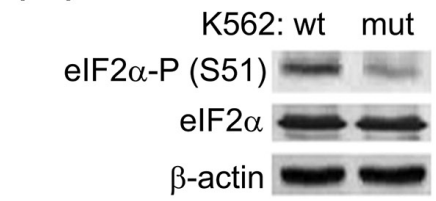

$(\mathrm{B})_{3}$

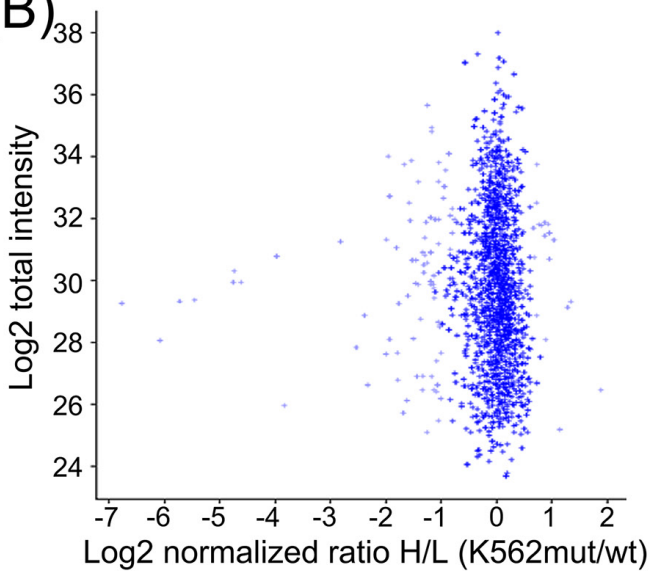

(D)

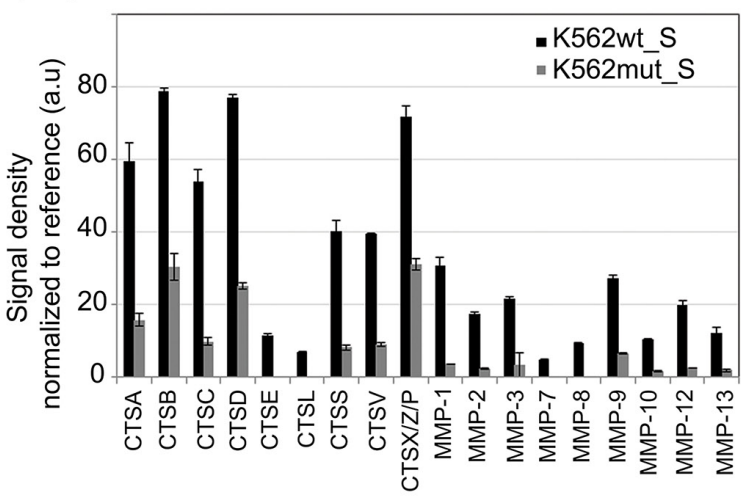

$(\mathrm{F})$

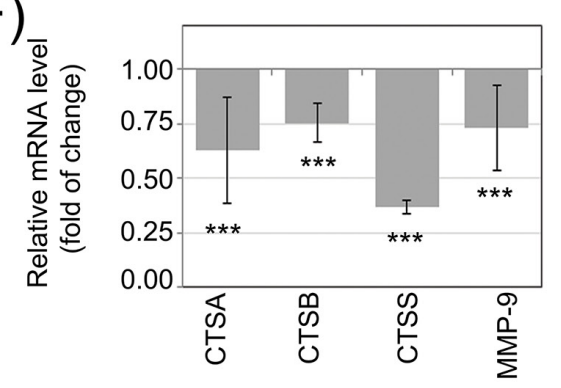

(C)

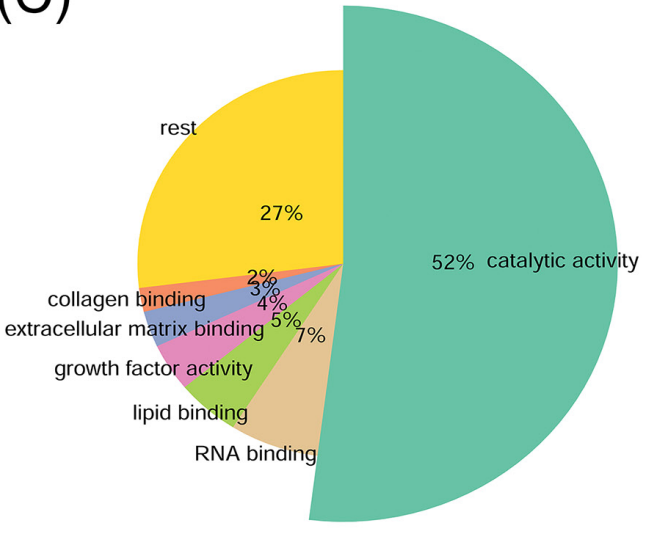

$(\mathrm{E})$

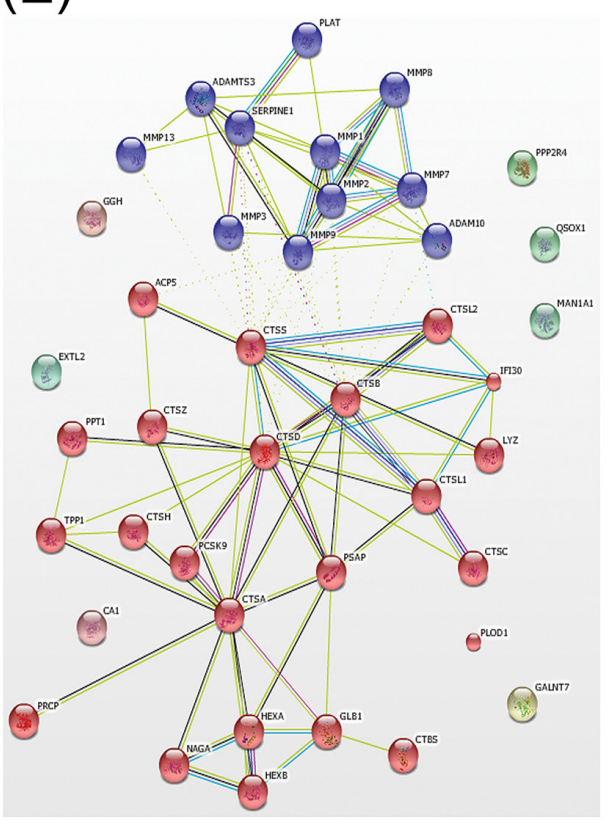

Figure 1: Influence of eIF2 $\alpha$ phosphorylation on the profile of enzymes secreted by K562 cells. A. eIF2 $\alpha$-P level in FACSsorted K562 expressing GFP alone (K562wt) or GFP and the eIF2 $\alpha$-S51A mutant (K562mut) was analyzed by immunoblot; $\beta$-actin is shown as protein loading control. B-C. $18 \mathrm{~h}$ serum-free conditioned medium cleared by multistep centrifugation from K562wt (K562_S) and K562mut (K562mut_S) was analyzed by quantitative SILAC LC-MS/MS. Pooled results from 3 independent experiments are presented. (B) Volcano plot showing normalized ratio of protein abundance as $\log 2$ normalized ratio heavy to light (K562mut_S and K562wt_S) (x-axis) and summed peptides intensities as $\log 2$ total intensities (y-axis). (C) Gene Ontology assignment of proteins with significantly different abundance between K562wt_S and K562mut_S to biological processes. D. Abundance of secreted cathepsins (CTS) and matrix metalloproteases (MMP) were analyzed in S-medium by antibody array. Signal density was analyzed using Image J software and normalized to reference. Graphs are mean protein level \pm SEM for $n=3$ independent samples. E. STRING database mapping of proteases identified using SILAC and antibody array. Nodes of clusters are displayed using MCL clustering algorithm with parameter value 2. F. mRNA levels of selected enzymes were quantified by real-time RT-PCR and shown as mean fold change \pm SEM for $n=3$ independent samples of K562mut to K562wt cells *** $<0.001$ in Student's t-test. 
was significantly decreased compared to control cells, suggesting that reduced secretion of enzymes is due to decreased transcription of the corresponding genes.

Previously we showed, that in K562 and BV173 cell lines phosphorylation of eIF $2 \alpha$ regulates proleukemic pathways at least partially independently on BCR-ABL activity, even upon imatinib treatment [22]. To confirm that secretion of stroma-modifying enzymes can also depend on the phosphorylation status of eIF $2 \alpha$ but not solely on the activity of BCR-ABL, the K562wt cells were treated with imatinib, a specific inhibitor of BCR-ABL tyrosine kinase. Whereas BCR-ABL kinase activity was inhibited after 18 hrs incubation with imatinib, as confirmed by the lack of STAT5 phosphorylation, the cells remained alive and the profile of secreted enzymes analyzed by antibody arrays did not change (Supplementary Figure S2A-2C). Therefore we postulate that phosphorylation of eIF $2 \alpha$ regulates the secretion of stroma-modifying enzymes in CML cells.

\section{Decreased eIF2 $\alpha$ phosphorylation reduces the invasive potential of leukemia cells}

Differences in the abundance of secreted proteases could lead to changes in the ability of CML cells to degrade the ECM. One of the main components of the ECM is collagen and its derivative - gelatin. Both CTSs and MMPs, the two groups of secreted enzymes identified in our proteomic screen, possess collagenolytic and gelatinolytic activity. We therefore hypothesized that conditioned media from K562mut cells would have reduced ability to digest gelatin. We verified this hypothesis using gelatinase zymography. We found that the efficiency of gelatin degradation by K562mut_S was significantly decreased compared to K562wt S (Figure 2A). There were two bands visible in the gelatinpolyacrylamide gel, suggesting that the samples contained gelatinases with molecular weights of around $90 \mathrm{kDa}$ and $60 \mathrm{kDa}$, respectively. The $90 \mathrm{kDa}$ gelatinase could represent MMP-9, and the $\sim 60 \mathrm{kDa}$ band could correspond to one of several MMPs: MMP-2, MMP-8 or MMP-14. Of these latter three, however, only MMP-2 has gelatinolytic activity, suggesting that it is likely the $60 \mathrm{kDa}$ gelatinase.

Since K562mut cells degrade the ECM at a slower rate than $\mathrm{K} 562 \mathrm{wt}$, we further hypothesized that the reduced eIF2 $\alpha-\mathrm{P}$ in K562mut cells may result in the impairment of their invasive potential. To test this hypothesis, we used the BD Biocoat Tumor Invasion System. This system measures the ability of cells to penetrate from the upper chamber to the lower chamber of a transwell through a mesh coated with matrigel. An uncoated mesh is used as control to distinguish between bona fide invasion and simple migration. The number of cells that invaded into the bottom chamber through matrigel coating after $18 \mathrm{~h}$ was significantly lower for K562mut cells than for K562wt cells (Figure 2B, matrigel). On the other hand, the number of cells that migrated through the uncoated mesh was not significantly different between the two cell lines (Figure $2 \mathrm{~B}$, mesh). This suggests that reduced phosphorylation of eIF $2 \alpha$ may impair the invasiveness of leukemia cells.

We previously showed that progression of CML from chronic phase to blast crisis is accompanied by increased eIF2 $\alpha$ phosphorylation [22]. Moreover, CML progression is known to be associated with increased invasiveness of the cancer cells [14]. We therefore expected that leukemia cells at blast crisis would show higher invasiveness in the transwell assay than chronic phase cells or untransformed healthy cells. We verified this hypothesis using Lin-CD34+ primary cells from healthy donors or CML patients. The cells at blast crisis (CML-BC) showed over 2-fold higher invasion potential than normal cells from healthy donor $(\mathrm{N})$ and 1.85-fold higher than cells at chronic phase (CML-CP) (Figure 2C). Taken together, this data suggests that increased phosphorylation of eIF $2 \alpha$ in leukemia cells could support invasiveness of cancer cells and in that way play a role in CML progression.

\section{eIF2 $\alpha$-P-dependent secretome of CML cells evokes ECM degradation by fibroblasts and their invasive potential}

Stimulation of phenotypic changes of bone marrow fibroblasts was demonstrated to accompany progression of multiple types of leukemia, such as multiple myeloma [29] and chronic lymphocytic leukemia [30]. In order to study the influence of soluble factors secreted by K562 cells on stromal cells, we added conditioned media from K562wt and K562mut cultures to cultures of HS-5 cells, a line of immortalized human bone marrow stromal fibroblasts. The HS-5 line can support the growth of hematopoietic progenitor cells [31] and is commonly used as a model of bone marrow stroma. Conditioned media (S) from HS-5 (HS-5_S), K562wt (K562wt_S) and K562mut (K562mut_S) cell cultures was cleared by multistep ultracentrifugation and used for further assays.

We first tested the ability of CML-conditioned media to regulate proliferation (Figure $3 \mathrm{~A}$ ) and cell death (Figure 3B) of stromal fibroblasts. K562wt_S, but not K562mut_S, significantly reduced the rate of proliferation of HS-5 cells (Figure 3A). In contrast, cell death rates remained constant under all conditions as indicated on the dot plots (Figure 3B). We then verified if components secreted by K562 cells could affect fibroblast migration and invasiveness. K562wt_S-exposed HS-5 cells had increased velocity of wound closure compared to HS-5 cells exposed to K562mut_S (Figure 3C). Next we found that migration rate of HS-5 cells was not significantly changed in the presence of soluble factors secreted by K562wt compared to K562mut cells (Figure 3D, mesh). However, K562wt_S significantly increased the ability of HS- 5 cells to penetrate through matrigel in 
a transwell assay (Figure 3D, matrigel). Next, to confirm that factors secreted by K562 cells have an impact on ECM degradation by HS-5 cells, we measured the ability of cells cultured in the presence of different conditioned media to degrade fluorescent gelatin (Figure 3E). We found that K562wt S and K562mut_S enhanced the ability of HS-5 cells to degrade gelatin, but the effect evoked by K562wt_S was significantly ( 2-fold) higher than that evoked by K562mut_S (Figure 3E).

We then wanted to see if the effects on HS-5 cell invasiveness caused by K562 cell conditioned media can be recapitulated by media collected from primary leukemia cell cultures (Figure $3 \mathrm{~F}$ and 3G). Indeed, media conditioned by blast crisis leukemia Lin-CD34+ cells increased the ability of HS-5 cells to both penetrate through matrigel in a transwell assay (Figure 3F) and to degrade fluorescent gelatin (Figure 3G) compared to media conditioned by Lin-CD34+ cells from chronic phase or a healthy donor. In summary, these results suggest that modification of protease secretion by eIF $2 \alpha$ phosphorylation in leukemia cells, which accompanies disease progression, may affect the invasive potential of not only leukemia cells themselves, but also of surrounding cells in the tumor stroma.
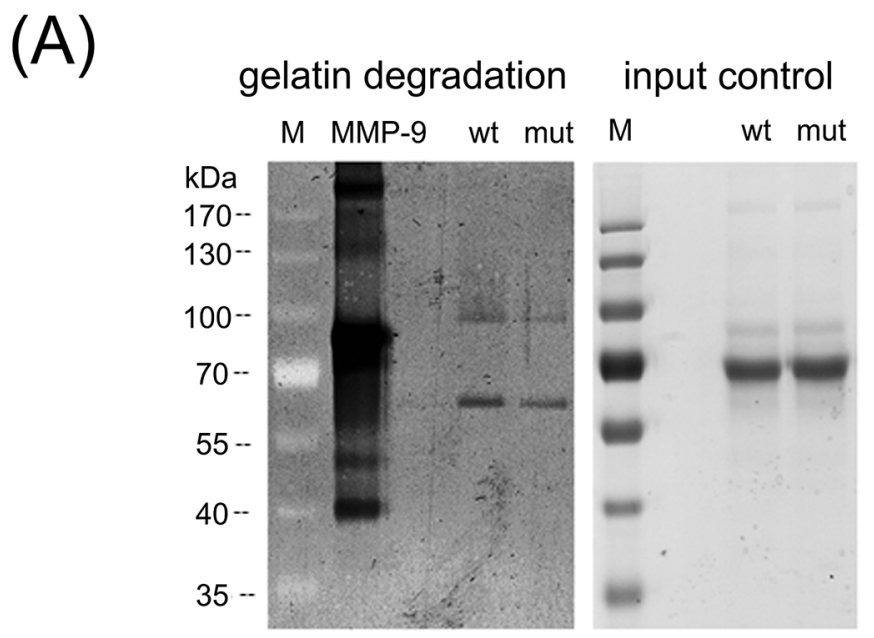

(B)

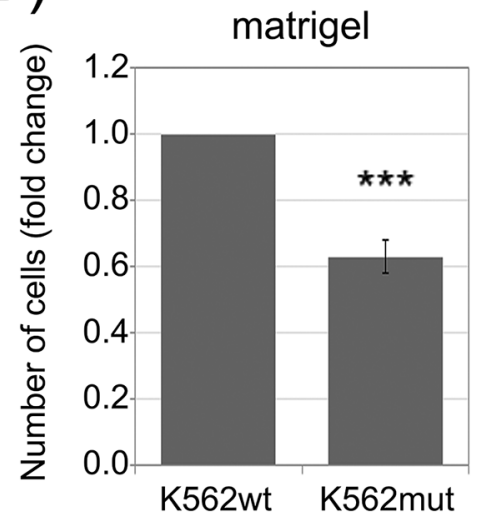

mesh

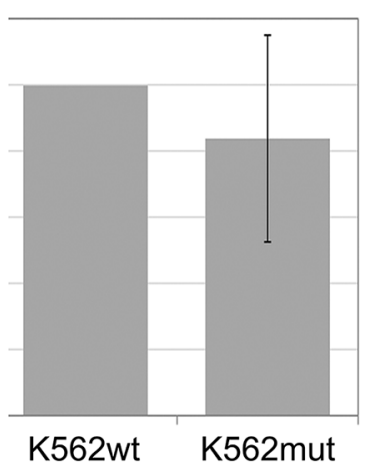

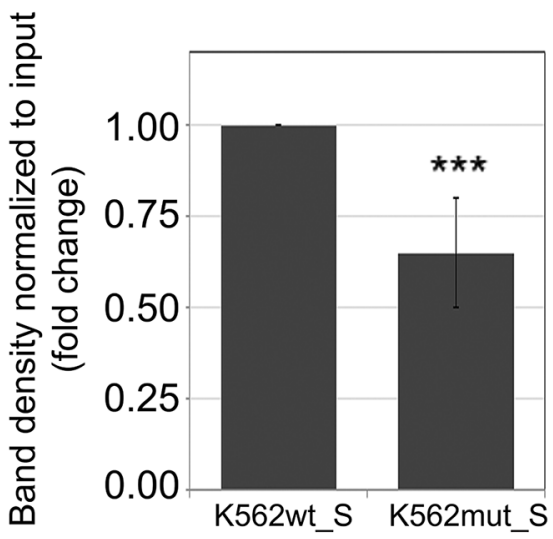

(C)

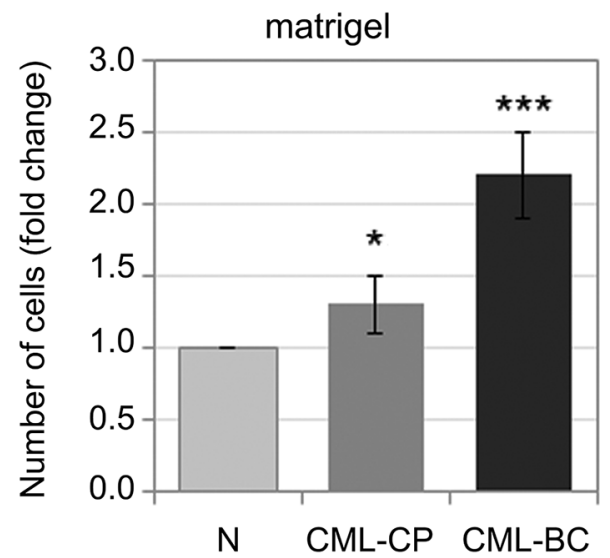

Figure 2: Impact of phosphorylation of eIF $2 \alpha$ in leukemia cells on their invasive properties. A. Gelatinase activity of S-media from K562wt and K562mut cells was analyzed by zymography. Proteins from conditioned media were separated on a polyacrylamide gel containing $5 \mathrm{mg} / \mathrm{ml}$ gelatin and gelatin digestion was detected by Coomassie staining (dark areas). 5ng of recombinant MMP-9 was used as positive control. Proteins form conditioned media separated on a polyacrylamide gel without gelatin, stained with Coomasie were used as input control; M-molecular weight protein ladder. Graphs show mean fold change of band intensity normalized to input $\pm \mathrm{SEM}, \mathrm{n}=3$ independent samples. B. K562wt and K562mut cell invasion was tested by the transwell assay on matrigel-coated meshes (matrigel, left graph). Migration of cells through the uncoated mesh was measured to account for changes in overall cell motility (mesh, right graph). Graphs represent the mean fold change of the number of cells in the bottom chamber \pm SEM, $n=3$. C. Invasion of Lin-CD34+ normal (N) and CML primary cells from chronic phase (CML-CP) and blast crisis (CML-BC) was measured as in B. ${ }^{* * *} \mathrm{p}<0.001,{ }^{*} \mathrm{p}<0.05$ in Student's t-test. 
(A)

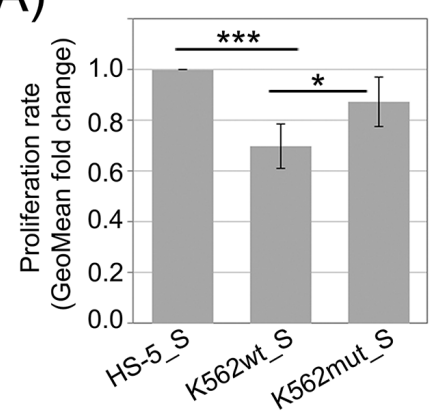

(C)

Oh
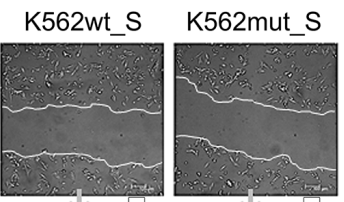

$24 h$
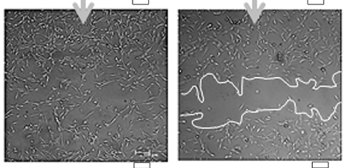

(B)

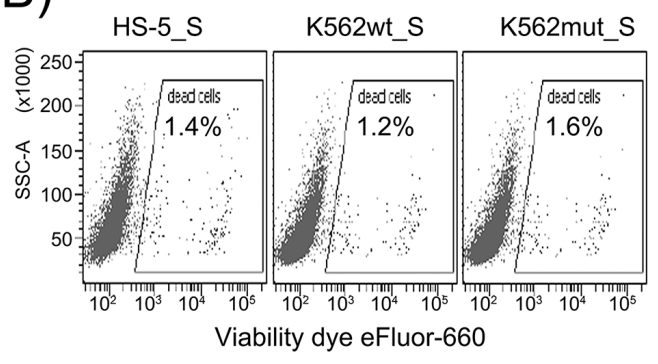

(D)
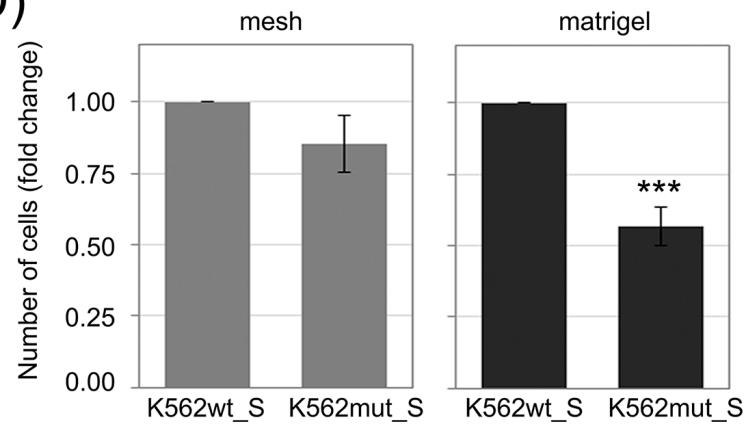

(E)
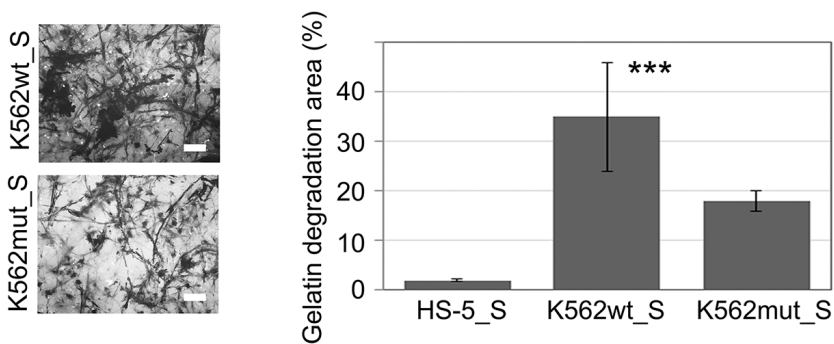

$(\mathrm{F})$

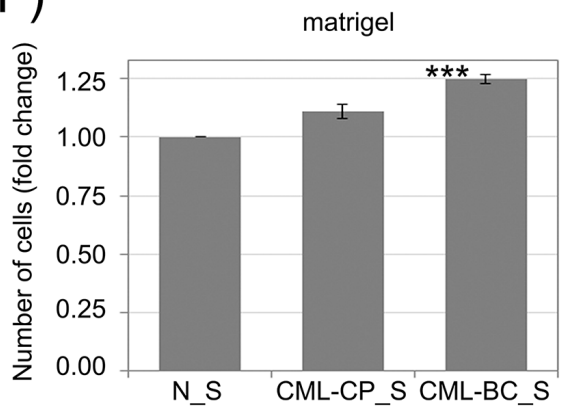

(G)

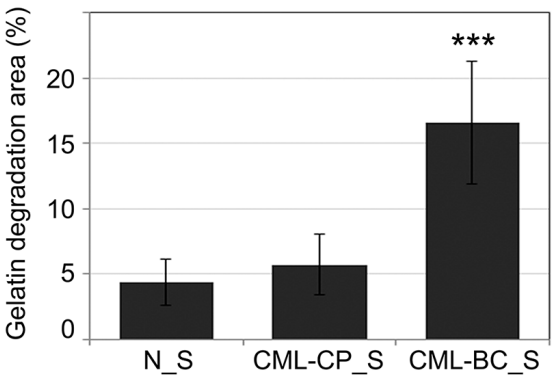

Figure 3: Influence of eIF2 $\alpha$ phosphorylation on the invasion potential of HS-5 stromal fibroblasts. HS-5 cells were cultured in conditioned media cleared by multistep centrifugation (K562wt S, K562mut_S or HS-5 S). A. Proliferation rate was assayed by flow cytometry. Bars correspond to mean fold change of proliferation dye fluorescence (GeoMean) at $24 \mathrm{~h}$ and $72 \mathrm{~h} \pm \mathrm{SEM} ; \mathrm{n}=4 \mathbf{B}$. Flow cytometry analysis of cell death levels in HS-5 cells cultured in the presence of conditioned media from different cultures. Typical scatterplots for each culture condition are shown, with side scatter area (SSC-A; y-axis) plotted against viability dye eFluor 660 signal intensity. Gate used to detect dead cells is indicated on each plot C. Monolayers of HS-5 cells cultured in the presence of K562wt_S or K562mut_S were subjected to the wound healing assay. Representative images out of 3 independent experiments of wound closure immediately after wounding $(0 \mathrm{~h})$ and after $24 \mathrm{~h}$ are shown. Scale bar $=100 \mu \mathrm{m} \mathrm{D}$. HS-5 cells were subjected to the transwell invasion assay as in Figure 2B, $\mathrm{n}=3$ E. Gelatin degradation by HS-5 cells cultured in S medium, as indicated, was quantified using OregonGreen-labeled gelatin. Representative images of fluorescent gelatin (grey) are shown in the left panel. Gelatin degradation is apparent as black areas on a grey background. Scale bar $=10 \mu \mathrm{m}$. Right panel shows mean percentage of gelatin degradation area normalized to cell number \pm SEM; $\mathrm{n}=3$ independent experiments $\mathbf{F}$, G. Matrigel invasion (F) and gelatin degradation (G) assays were performed as in D. and E., respectively, on HS-5 cells cultured in media conditioned by Lin-CD34+ cells from a healthy donor (N_S), chronic phase CML (CML-CP S) or blast crisis (CML-BC_S). ${ }^{* * *}$ p $<0.001$ in Student's t-test. 


\section{eIF2 $\alpha$ phosphorylation-dependent ATF4- mediated regulation of enzyme secretion by leukemia cells}

Phosphorylation of eIF $2 \alpha$ was demonstrated to modify level of ATF4 protein synthesis at the step of mRNA translation [32]. On the other hand, according to the Nencki Genomics Database [33], which contains consensus sequence of regulatory regions (Supplementary Figure S3), there are motifs possibly recognized by ATF4 transcription factor in selected CTSs and MMPs. The schematic representation of the likely functional ATF4 binding motif instances in the experimentally identified gene regulatory regions: TF bindings sites and DNase 1 open chromatin regions, FANTOM promoters and enhancers are presented in the Figure 4A. This analysis suggests that decreased level of ATF 4 in cells with reduced eIF $2 \alpha$ phosphorylation could account for the changes in protease secretion (Figure 1D) and mRNA levels (Figure $1 F)$. Indeed, we observed reduction of ATF4 protein in K562mut cell lysates by immunoblot (Figure 4B). In agreement with previous reports [32] this effect did not result from reduced ATF4 mRNA level (Figure 4C). Based on these results, we hypothesized that ATF4 levels would increase as a function of CML progression. Indeed, primary blast crisis CML cells showed 1.45-fold higher levels of ATF4 than chronic phase CML cells in a flow cytometry assay, used instead of Western blotting due to limited number of cells (Figure 4D).

In order to investigate the influence of ATF4 on protease secretion, K562 cells were transduced with shRNA specific to ATF4 mRNA (shATF4) to downregulate its expression, or a negative control shRNA (shNEG). The efficiency of ATF4 knockdown by different shRNAs was deteced by real time RT-PCR (Figure 5C) and confirmed by immunoblot (Figure 5A). This showed that two shRNAs (named as $\mathrm{c} 1$ and $\mathrm{c} 3$ ) were sufficiently silencing ATF4, among which shRNA-c1 was the most effective at both, protein (Figure 5A) and mRNA (Figure 5C) levels. We then measured the effect of ATF4 silencing on CTS and MMP secretion by antibody array. The secretion of proteases by K562 cells was significantly reduced in cells expressing ATF4 shRNA-c1 (Figure 5B; representative blots are presented in Supplementary Figure S4). Consistently, mRNA levels of all of the tested protease genes were also significantly downregulated in cells with ATF4 knockdown mediated by shRNA-c1 (Figure 5C), suggesting that ATF4 may regulate the expression of proteases at the level of transcription. As the ATF4 silencing mediated by the shRNA-c3 was lower compared to shRNA-c1, the effect on the enzymes expression was moderated in case of CTSA and CTSB, however still significant in case of CTSS, MMP9 and MMP3 enzymes.

To determine the role of ATF4 in proliferation and sensitivity to imatinib, the shNEG and shATF4 transduced K562 cells ( $\mathrm{c} 1$ and $\mathrm{c} 3$ ) were untreated and treated with different concentrations of imatinib. In cells depleted with ATF4, the apoptosis rate in the AnxA5 assay was not increased as well as the clonogenic potential in the presence and absence of imatinib treatment was not reduced (Supplementary Figure S5A and S5B). Therefore, ATF4 does not regulate the proliferation of CML cells and their sensitivity to imatinib.

To verify the influence of ATF4 activity on the invasive potential of leukemia cells, we performed the matrigel transwell assay (Figure 5D). Cells expressing ATF4 shRNA, both, c1 and c3, had strongly reduced ability to invade through matrigel compared to control cells. We also hypothesized that media conditioned by K562 cells with ATF4 knockdown may have reduced ability to promote fibroblast invasiveness. Indeed, HS-5 cells cultured in media conditioned by K562 cells with ATF4 knockdown (shATF4_S), clones c1 as well as c3, degraded fluorescently labeled gelatin at a significantly slower rate than those cultured in media conditioned by control K562 cells (Figure 5E). Altogether, our results show that the effect of eIF $2 \alpha$ phosphorylation on protease secretion is ATF4-dependent. The eIF2 $\alpha-\mathrm{P} / \mathrm{ATF} 4$ axis is likely to play a central role in the potentiation of invasive properties of leukemia cells, as well as influence their cross-talk with bone marrow stromal fibroblasts.

\section{DISCUSSION}

The interactions between cancer cells and their microenvironment are crucial for the development of leukemia. A variety of cytokines, growth factors, adhesion molecules and ECM remodelling proteins are secreted by both tumor and non-tumor cells, mediating cellular communication within the cancer microenvironment and providing a suitable niche for cancer cell persistence. This crosstalk is also involved in disease progression and development of resistance to therapy.

We previously showed that enhanced phosphorylation of eIF2 $\alpha$ in CML cells potentiates leukemogenesis and accompanies CML progression from chronic phase to blast crisis [22]. Here, we provide evidence suggesting that induction of stress response in CML cells, which is associated with eIF2 $\alpha$ phosphorylation, participates in the remodeling of extracellular milieu, which can contribute to cancer development. We demonstrate that reduced phosphorylation of eIF $2 \alpha$ in CML cells correlates with decreased secretion of ECM-modifying enzymes and blocks cells invasiveness. This is in agreement with a recent report showing that triggering of ER stress and activation of the PERK/eIF $2 \alpha-\mathrm{P}$ axis is essential to the epithelial-to-mesenchymal transition [34], a process that promotes invasiveness. Importantly, inhibition of BCR-ABL activity by imatinib was not able to diminish amounts of secreted enzymes confirming that eIF $2 \alpha-$ dependent signaling is responsible for such regulation. 
(A)

\section{ATF4 binding motif instances}

MMP-3

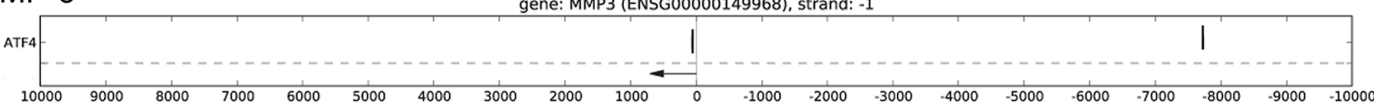

MMP-9 gene: MMP9 (ENSG00000100985), strand: 1

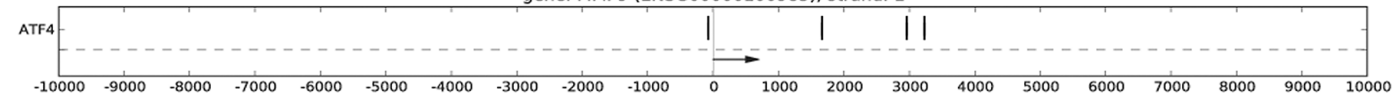

CTSA gene: CTSA (ENSG00000064601), strand: 1

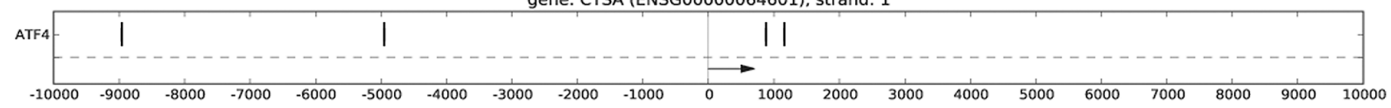

CTSB gene: CTSB (ENSG00000164733), strand: -1

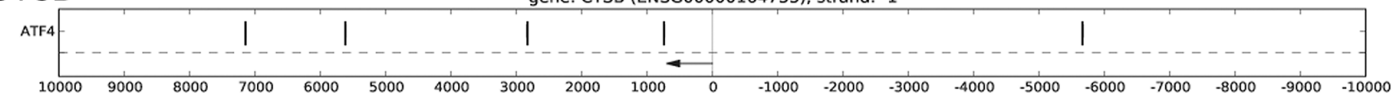

CTSS gene: CTSS (ENSG00000163131), strand: -1

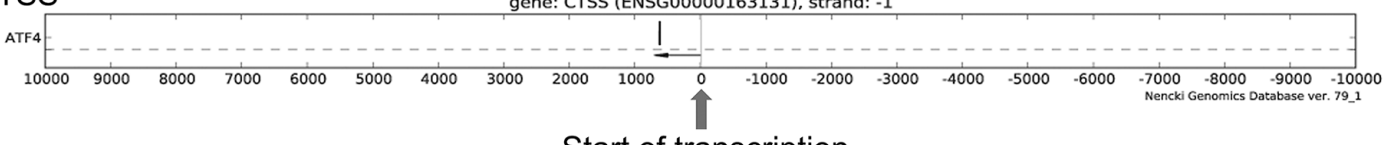

Start of transcription

(B)
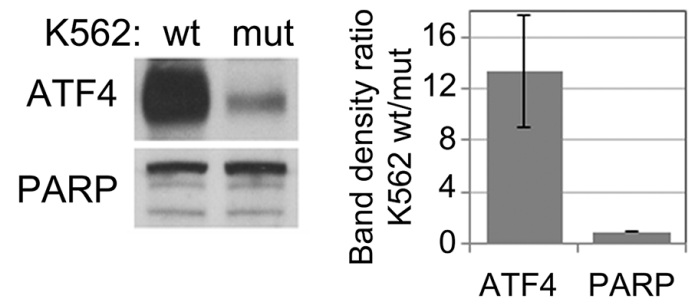

(D)

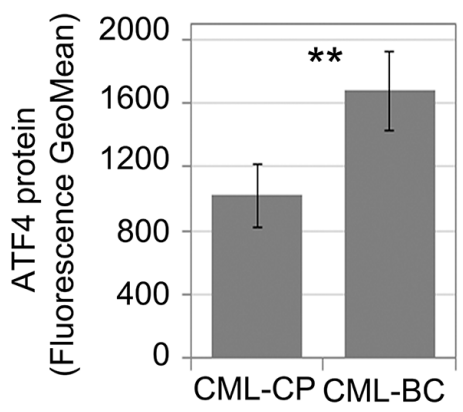

(C)

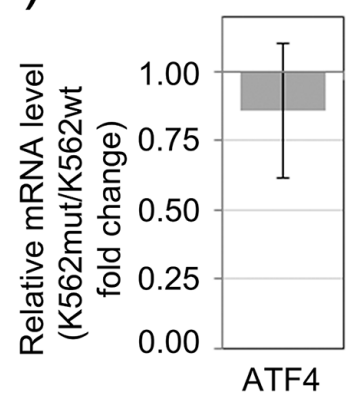

Figure 4: Synthesis of ATF4 protein in leukemia cells is dependent of eIF2 $\alpha$ phosphorylation. A. Genomic locations of potential ATF4 binding motifs (black vertical dashes) in experimentally verified gene regulatory regions within 10kb from transcription start sites (TSS) of selected protease genes. Distance from the TSS is indicated on the X-axis. Direction of transcription is marked with an arrow. B. Protein level of ATF4 in K562wt and K562mut cells analyzed by immunoblot; PARP was used as loading control. Band density was quantified and expressed as mean ratio in K562wt to K562mut cells \pm SEM; $\mathrm{n}=3$ C. Level of ATF4 mRNA was determined by real-time RT-PCR, and is shown as fold change of K562mut to K562wt cells. D. Level of ATF4 protein in Lin-CD34+ primary cells from CML-CP and CML-BC was analyzed by flow cytometry. Fluorescence GeoMean values of CML-BC to CML-CP $\pm \mathrm{SEM}$; $\mathrm{n}=3$ independent samples. $* * p<0.005$ in Student's t-test. 
(A)

PARP ATF4
(B)

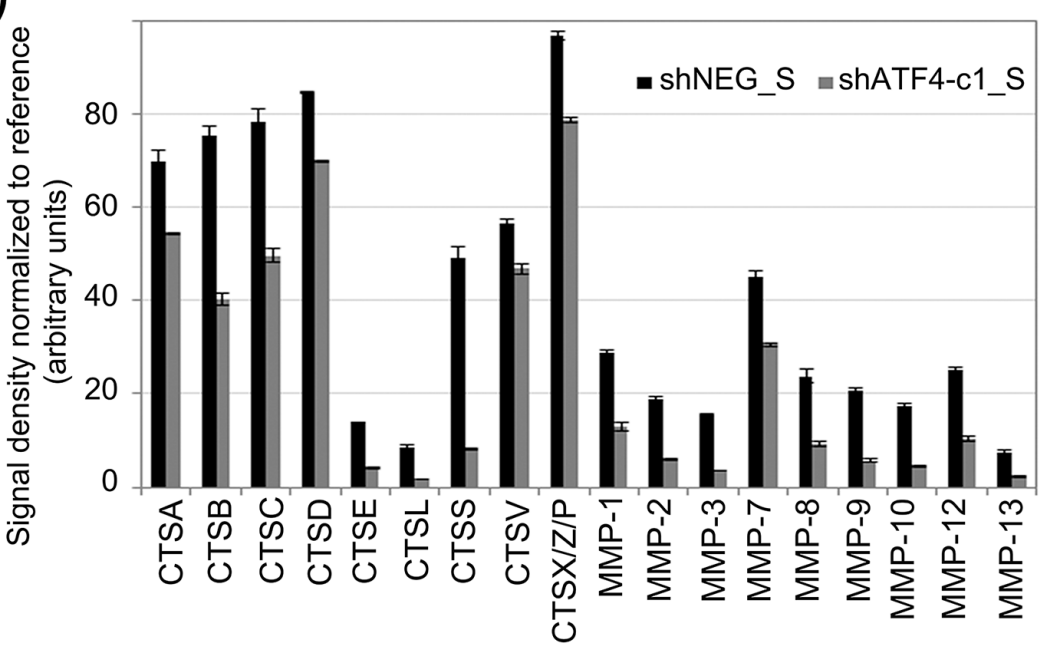

$(\mathrm{C})$

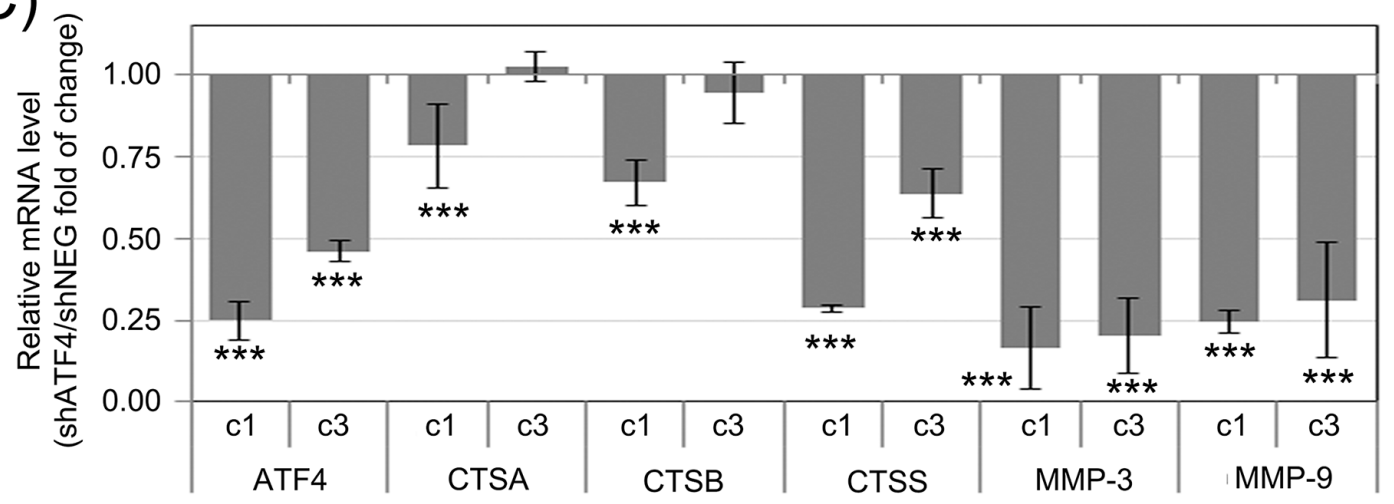

(D)

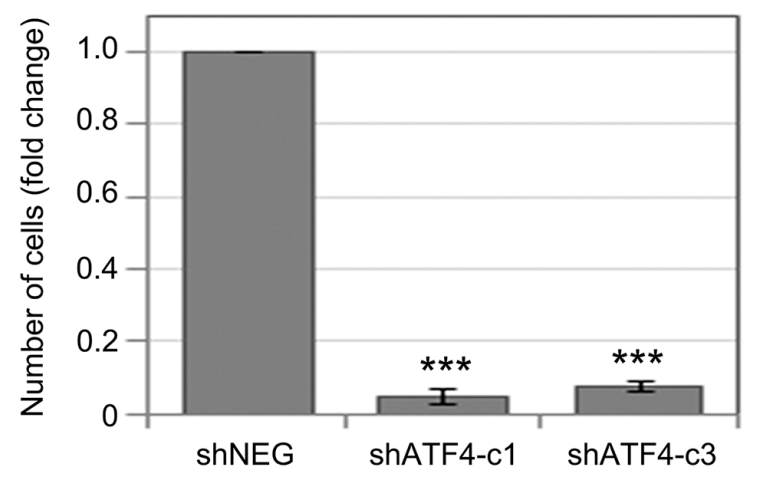

(E)

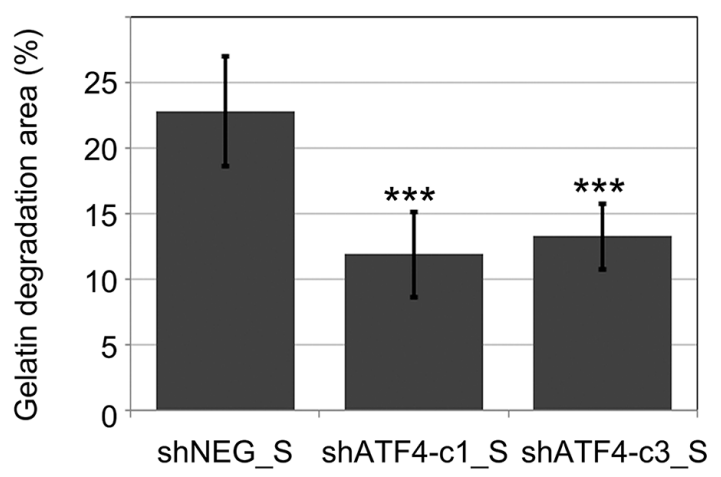

Figure 5: Influence of ATF4 on protease secretion and invasive potential of CML cells and stromal fibroblasts. ATF4 was depleted in K562 cells by viral transduction of 4 different clones of shRNA specific to ATF4 (shATF4-c1 - c4); Non-targeting shRNA (shNEG) was used as control A. ATF4 protein level was quantified in whole cell lysates by immunoblot; PARP was used as loading control. B. Protease abundance was measured by antibody array in serum-free conditioned media from cultures of K562 expressing shATF4 (shATF4-c1_S) and control shRNA (shNEG_S). Signal density was analyzed using Image J software and normalized to reference. Graphs are mean protein level \pm SEM for $n=3$ independent samples $\mathbf{C}$. Level of mRNA of selected enzymes was measured by real-time RT-PCR and is shown as mean fold change between K562 cells expressing shATF4-c1 or shATF4-c3 and shNEG \pm SEM for n=3 independent samples D. Matrigel invasion of K562 expressing the indicated shRNA constructs was measured using the transwell assay, as in Fig. 2B; $\mathrm{n}=3$ independent experiments E. Gelatin degradation by HS-5 cells cultured in shATF4-c1_S or shATF4-c3_S and shNEG_S was measured as in Fig. 3E; $\mathrm{n}=3 .{ }^{* * *} \mathrm{p}<0.001,{ }^{*} \mathrm{p}<0.05$ in Student's t-test. 
Moreover, we demonstrate for the first time the induction of the invasive potential of bone marrow stromal fibroblasts upon factors secreted by CML cells in an eIF $2 \alpha-P$ dependent manner. This phenomenon may assist the disruption of bone marrow architecture during leukemia progression and facilitate liberation of cancer cells to the bloodstream. It was shown recently that secretion of cytokine-like leukemia inhibitory factor 1 evokes invasiveness of stromal fibroblasts by turning them into the cancer associated fibroblasts (CAFs) [35]. Induction of phenotypic changes in bone marrow fibroblasts was demonstrated to promote progression of multiple myeloma [29] and chronic lymphocytic leukemia [30, 36]. CAFs were also shown to assist the invasion of cancer cells in breast cancer [37] or gastric carcinoma [38].

We show that phosphorylation of eIF $2 \alpha$ in CML cells modifies the expression and secretion of proteases belonging to the cathepsin and matrix metalloprotease families. Moreover, the increased activity of these enzymes supports extracellular matrix degradation by fibroblasts. These findings are in agreement with the previous observations that stimulation of secretion of MMP-9 accompanies CML progression and mediates the degradation of extracellular matrix [13-15]. Increased secretion of MMP-9 by chronic B-lymphocytic leukemia (B-CLL) was also shown to play a significant role in the invasiveness of these cells [16]. Other MMPs that we also showed to be regulated by eIF $2 \alpha-\mathrm{P}, \mathrm{MMP}-7$ [17] and MMP-12 [18], were found to potentiate invasion of leukemia cells. MMP-3, also known as Stromelysin-1, another protease identified in our screen, has the ability to cleave a broad spectrum of ECM components [39] and activates other MMPs such as MMP-9 [40] and MMP-7 [41]. Simultaneous up-regulation of MMPs was observed in several diseases [42-44]. Contrary to MMPs, the significance of cathepsins released by leukemia cells has not been studied so far. Nevertheless, increased level of secreted CTSS or CTSB have been shown to be associated with metastasis in other cancer types [4547]. Furthermore, CTSX is upregulated in metastatic gastric cancer [48], enhanced levels of CTSB and CTSL accompany malignant ovarian tumors [49], and CTSS directly supports invasion of hepatocellular carcinoma cell lines [50]. It is worth noting that cathepsins display the highest activity in the acidic and low oxygen conditions, which occur in dense solid tumors but also in the bone marrow niche. Taking together, cathepsins secreted by leukemia cells could play a significant role in supporting the invasiveness of CML cells, which might be especially important under the hypoxic state in the bone marrow.

Finally, we demonstrated that the effects of eIF $2 \alpha$ phosphorylation on protease secretion, but not on imatinib sensitivity are likely mediated by ATF4. We postulate that ATF4 production in leukemia cells plays a significant role in the regulation of extracellular matrix dynamics and invasiveness of both CML and stromal cells. Our claims are supported by the recently reported involvement of ATF4 in metastasis of different tumors. First, circulating metastatic cancer cells have increased level of ATF4 [51]. Moreover, hypoxia occurring in breast cancer stimulates the migration of cancer cells upon activation of the PERK/eIF2 $\alpha-\mathrm{P} / \mathrm{ATF} 4$ signaling pathway [52]. Furthermore, up-regulation of ATF4 in osteosarcoma cells accompanies tumor progression and supports metastasis [53]. In addition, ATF4 was postulated to stimulate metastasis in human fibrosarcoma cells [54]. Finally, increased expression of ATF4 in esophageal squamous cell carcinoma correlates with invasion and metastasis, an effect attributed to increased transcription of MMP-2 and MMP-7 [55]. This is consistent with our findings that MMP-2 and MMP-7 are downregulated upon ATF4 knockdown. All these data strongly support the pro-invasive role of ATF4, and are in full agreement with our results.

Our current and previous data identified the PERK-eIF2 $\alpha$-ATF4 axis as an interesting target for pharmacological intervention in CML. PERK inhibitors, GSK2606414 and its derivative GSK2656157 optimized for clinical investigation have been tested in different types of tumors such as pancreatic cancer and multiple myeloma [56, 57]. These compounds showed high therapeutic potential, however their still require safety and toxicity evaluation.

\section{SUMMARY}

We demonstrate that the enhanced phosphorylation of eIF $2 \alpha$ is associated with secretion of enzymes that catalyze extracellular matrix degradation, thus inducing cancer-supportive changes in the microenvironment. Phosphorylation of eIF $2 \alpha$ in CML cells potentiates the invasiveness of leukemia cells as well as of bone marrow stromal fibroblasts. Modification of ATF4 protein levels in an eIF $2 \alpha$-dependent manner is likely to account for the observed effects on protease expression and secretion. Overall, our results point to eIF $2 \alpha$ and ATF4 as potential therapeutic targets in leukemia.

\section{MATERIALS AND METHODS}

\section{Cell culture and treatment}

K562 cells (ATCC®CCL-243) and HS-5 cells (ATCC $\AA C R L-11346)$ were obtained from American Type Culture Collection. K562 and HS-5 cell lines were cultured in RPMI-1640 (SIGMA) supplemented with $100 \mathrm{U} / \mathrm{ml}$ penicillin, $100 \mu \mathrm{g} / \mathrm{ml}$ streptomycin, $2 \mathrm{mM}$ L-glutamine (SIGMA) and 10\% FBS (v/v, Biowest). CML-CP cells from patients at diagnosis $(n=3)$ and CML$B C$ cell samples $(n=3)$ were obtained from Stem Cell and Leukemia Core Facility of the University of Pennsylvania (Philadelphia, PA), and normal hematopoietic cells from healthy donors were purchased from Cambrex Bio Science 
(Walkersville, MD). Lin-CD34+ cells were selected by magnetic sorting using the EasySep negative selection human progenitor cell enrichment cocktail followed by human CD34 positive selection cocktail (\#19056 and \#18056, respectively; StemCell Technologies). LinCD34+ cells were cultured in StemSpan H3000 medium (StemCell) supplemented with $1 \mathrm{ng} / \mathrm{ml}$ SCF, $0.2 \mathrm{ng} / \mathrm{ml}$ IL-3, 0.2ng/ml IL-6, 1ng/ml FIT3 (PeproTech). Cells were grown under standard conditions $37^{\circ} \mathrm{C}, 5 \% \mathrm{CO}_{2}$.

\section{Transfection}

Viral vector pMSCV-IRES-GFP or pMSCV-IRESGFP/eIF $2 \alpha$-S51A that express both GFP and untagged eIF2 $\alpha$-S51A were expressed in K562 cells as described earlier [58]. Cell expressing only GFP are denoted in this manuscript as K562wt and cells expressing eIF2 $\alpha$-S51A and GFP are described as K562mut. GFP-expressing cells were sorted using FACS Aria (BD).

\section{Creation of stable ATF4 knock-down K562 cell line}

ATF4 was silenced in human K562 cells with MISSION TRC shRNA Lentiviral Particles (\#SHCLNVNM_001675/TRCN0000013573, SIGMA); 5 different clones. For control infection, MISSION TRC2 pLKO.5-puro Non-Mammalian shRNA Control Transduction Particles were used (\#SHC202V, SIGMA). Cells were seeded in 96-well plate (8000 cells/well) and transduced with lentiviral particles at multiplicity of infection of 5 . After 3 days, puromycin was added at $1 \mu \mathrm{g} / \mathrm{ml}$. Antibiotic selection was performed for 10 days. As infection with shATF4-c5 turned to be lethal, only shATF4-c1-c4 were used for experiments.

\section{Conditioned medium collection}

For conditioning, cells were suspended in serumfree medium (unless otherwise stated) at a density of $4 \times 10^{5}$ cells $/ \mathrm{mL}$. After $18 \mathrm{~h}$, conditioned medium was collected and cleared from cellular debris and extracellular vesicles during multistep centrifugation at $4^{\circ} \mathrm{C}$ as follows: (1) $163 \mathrm{xg}$ for $5 \mathrm{~min}$; (2) $319 \mathrm{xg}$ for $5 \mathrm{~min}$; (3) $1277 \mathrm{xg}$ for 20min; (4) $10000 x g$ for $40 \mathrm{~min}$; (5) $110000 \mathrm{xg}$ for $1 \mathrm{~h}$ 40min (45Ti rotor, Beckman Coulter). Supernatant from the last centrifugation is designated as " $\mathrm{S}$ " throughout the manuscript and was used for experiments.

\section{SILAC LC-MS/MS}

Composition of secreted proteins in conditioned medium was studied after stable isotope labelling by amino acids in cell culture (SILAC) as described by Ong et al. [59]. Briefly, the cells were cultured in SILAC DMEM without L-Arginine and L-Lysine (Thermo Scientific) with $10 \%$ dialyzed FBS (Thermo Scientific) 'heavy medium' supplemented with stable isotope labelled ${ }^{13} \mathrm{C}_{6} \mathrm{~L}$-Arginine at $0.47 \mathrm{mM}$ and ${ }^{13} \mathrm{C}_{6}{ }^{15} \mathrm{~N}_{2}$ L-Lysine at $0.46 \mathrm{mM}$ final concentration (\#CLM-2265-H-0.1 and \#CNLM-291-H-0.1 accordingly from Cambrige Isotope Laboratories Inc.) or 'light medium' with non-labelled L-Lys and L-Arg (SIGMA) added at the same final concentration. After 6 population doublings (FACS analysis showed about $24 \mathrm{~h}$ per 1 doubling) labelled cells were collected, washed in serum-free SILAC DMEM and suspended in serum free medium heavy for K562mut or light for K562wt for $18 \mathrm{~h}$ (cells density $6 \times 10^{5} / \mathrm{ml}$ ). The experiment was repeated twice performing SILAC also in reverse mode. Efficiency of proteins labelling was verified to be above $98 \%$.

Soluble proteins from $\mathrm{S}$ from each variant were mixed in 1:1 ratio normalized to the number of cells. Samples were processed using filter-aided sample preparation (FASP) according to [60], and subjected to in-gel isoelectric focusing of peptides as described [61]. Each gel strip was then cut into 21 fragments. Peptides eluted from each fragment were separately subjected to separation by high pressure liquid chromatography (HPLC) and mass spectrometry analysis using LTQ Orbitrap Velos (Thermo Fisher Scientific). Data analysis was done using Mascot software followed by MaxQuant software for quantitative data analysis as previously described [62].

\section{Antibody arrays}

The profile of secreted proteases in serum-free $\mathrm{S}$ was determined using Human Protease Array Kit (\#ARY021, R\&D Systems) according to the manufacturer's protocol. Densitometry was performed using ImageJ software (National Institutes of Health) with Protein array analyzer plug-in. The values were normalized to density of 6 reference spots included in each membrane. The list of differentially secreted proteins identified by SILAC LCMS/MS and antibody arrays was subjected to physical and functional protein associations network search using STRING (http://string-db.org).

\section{Wound-healing assay}

Migration was assayed by wound healing experiments as previously described [63]. Time-lapse observations were performed for $48 \mathrm{~h}$ using Leica AF7000 Live Imaging System (Leica Microsystems) microscope equipped with an environmental chamber, and a 10x/0.40NA objective. Wound closure was calculated and expressed as percentage of the area of the initial wound (defined at 0 time point). Image analysis was performed using ImageJ.

\section{Trans-well migration and invasion assay}

Cell migration and invasion were examined using inserts with polycarbonate filters with FluoroBlock 
membrane $(8 \mu \mathrm{m}$ pore size; BD) either uncoated or coated with Matrigel (BD) following the manufacturer's protocol. Cells were labelled with long term cell tracker Dil (Life Technology) and seeded into the upper chamber in $24 \mathrm{~h}$ serum-free conditioned medium $\mathrm{S}$. The lower chamber was filled with $10 \%$ FBS $24 \mathrm{~h} \mathrm{~S}$. After $20 \mathrm{~h}$ of incubation, the invasive cells on the underside were visualized and counted under the Leica fluorescent microscope DMI6000 using a 10x objective (Leica Microsystems) in 16 random fields. The number of cells was quantified with ImageJ.

\section{Fluorescent gelatin degradation assay}

The matrix degradation assay was conducted as described previously [61], with modifications. Briefly, $1.5 \times 10^{4}$ cells stained with cell tracking dye CMAC (Life Technology) were seeded in serum-free conditioned $\mathrm{S}$ medium on dishes with glass-bottom (MatTek Corporation) coated with gelatin labelled with OregonGreen (Life Technologies) according to the manufacturer's protocol. Then cells were cultured for $18 \mathrm{~h}$ and images were taken with a Leica fluorescent microscope with a 10x objective. By using the Image J Analyze Particles plugin the total area covered by degradation holes in the fluorescent background was measured in multiple fields and normalized to the total number of seeded cells.

\section{Zymography}

Equal amount of protein from each serum free $\mathrm{S}$ medium (1.5mg) was subjected to gelatinase enrichment step using gelatin sepharose beads (GE Healthcare) for $1.5 \mathrm{~h}$ with rotation at $4^{\circ} \mathrm{C}$. Then the beads were washed and gelatinases were eluted for $45 \mathrm{~min}$ with $10 \%$ DMSO in WB buffer (50mM Tris- $\mathrm{HCl}$ pH 7.5, 150mM $\mathrm{NaCl}, 5 \mathrm{mM} \mathrm{CaCl} 2,0.02 \% \mathrm{NaN} 3$ ) with rotation at $4^{\circ} \mathrm{C}$, followed by centrifugation at $12000 \mathrm{xg}$ for $15 \mathrm{~min}$ at $4^{\circ} \mathrm{C}$. The supernatant was mixed with loading buffer (62.5mM Tris-HCl pH 6.8, 2\% SDS, 10\% glycerol, 0.01\% bromophenol blue) and loaded on $8 \%$ polyacrylamide gel containing $5 \mathrm{mg} / \mathrm{ml}$ gelatin (Sigma Aldrich). As positive control, 5ng of recombinant MMP-9 was used. Following electrophoresis at $100 \mathrm{~V}$, the gel was washed twice in $2.5 \%$ Triton-X100 for $25 \mathrm{~min}$ at room temperature followed by $60 \mathrm{~h}$ incubation at $37^{\circ} \mathrm{C}$ in the activity buffer $(50 \mathrm{mM}$ Tris$\mathrm{HCl} \mathrm{pH} 7.5,10 \mathrm{mM} \mathrm{CaCl} 2,1 \%$ Triton-X100, 0.02\% NaN3) with gentle agitation. The areas of gelatin degradation area were visualized using Coomasie Brilliant Blue staining. In parallel, the input control samples (collectec before addition of gelatin beads) were heat denatured and subjected to SDS-PAGE in $8 \%$ gel, followed by staining with Coomasie Brilliant Blue. Gel images were scanned using CanoScan Lide210 (Canon) and bands density was analyzed using Image $\mathrm{J}$.

\section{Western blotting}

Cells were washed with phosphate-buffered saline (PBS), pH 7.4 prior to lysis at $95^{\circ} \mathrm{C}$ in loading buffer containing: $50 \mathrm{mM}$ Tris- $\mathrm{HCl} \mathrm{pH} 6.8,10 \%$ glycerol and $2 \%$ SDS. After SDS-PAGE and transfer onto nitrocellulose, proteins were immunostained with the primary antibodies: mouse anti- $\beta$-actin (SIGMA), rabbit anti-phospho-eIF2 $\alpha$ (S51) (Invitrogen), mouse anti-eIF2 $\alpha$ (Cell Signaling), mouse anti-GAPDH (Merck Millipore), rabbit anti-ATF4 (ProteinTech), rabbit anti-PARP (Cell Signaling); followed by secondary antibodies conjugated with horseradish peroxidase (GE Healthcare). The proteins were visualized using ECL kit according to the manufacturer's instructions.

\section{RNA isolation and real-time RT-PCR}

Total RNA was isolated using TRIzol Reagent (SIGMA). $1 \mu \mathrm{g}$ of RNA was subjected to reverse transcription with M-MLV enzyme (Promega) and oligodT primers (SIGMA). Real-time PCR was performed using SensiFAST SYBR Kit (Bioline) on the 7900HT Fast Real-time PCR System (Applied Biosystems). Primers used for real-time PCR are presented in Supplement Table S2. After normalization to 18SrRNA the comparative $2^{-\mathrm{DD}} \mathrm{Ct}$ method was used to determine relative mRNA level [64].

\section{FACS analysis of ATF4 protein level}

The cells were fixed and permeabilized using PerFix EXPOSE kit from Beckman Coulter (\#PN B26976), according to the manufacturer's protocol. The cells were stained for $30 \mathrm{~min}$ at room temperature with the primary antibody against ATF4 conjugated with fluorochrome - Allophycocyanin using Zenon labelling kit (Life Technologies) appropriate for the antibody isotype. Isotype control antibody (Abcam) was labelled and used as a background staining control. Flow cytometry analysis was performed using LSR Fortessa (BD).

\section{Cell death assay}

Cell were labeled with viability dye eFluor 660 (eBioscience), according to the manufacture's protocol, followed by analysis of cell death by flow cytometry (LSR Fortessa).

\section{Proliferation assay}

Cells were labelled with $10 \mu \mathrm{M}$ cell proliferation dye eFluor 670 (eBioscience) according to the manufacture's protocol and then cultured for 72 hours in conditioned medium. Fluorescence intensity of the cells was measured by flow cytometry (LSR Fortessa) on the staining day and in $24 \mathrm{~h}$ intervals. 


\section{Statistics}

All data are shown as mean \pm SEM of at least three independent experiments (with duplicates included in each experiment). Student's t-test or one-way analysis of variance (ANOVA) were used to verify statistical significance; ${ }^{*} \mathrm{p}<0.05 ;{ }^{*} \mathrm{p}<0.005 ; * * * \mathrm{p}<0.001$.

\section{ACKNOWLEDGMENTS}

The authors would like to acknowledge: Michal Dabrowski PhD and the Laboratory of Bioinformatics at the Nencki Instutitute for in sillico analysis of the presence of ATF4 recognition motifs in CTSs and MMPs genes; Izabela Rutkowska-Wlodarczyk PhD (the Nencki Institute) for a kind gift of recombinant MMP-9 used as positive control in zymography and Pawel Niewiadomski $\mathrm{PhD}$ (Centre of New Technologies in Warsaw) for help with the manuscript editing.

\section{CONFLICTS OF INTEREST}

The authors disclose no conflict of interests.

\section{ETHICAL APPROVAL STATEMENT}

Studies were approved by the Temple University Institutional Review Board (\#11492).

\section{GRANT SUPPORT}

This work was supported by the Polish Ministry of Science and Higher Education Iuventus Plus grant IP2011 043071 to P.P-B. and the National Science Centre research grants: DEC-2014/15/D/NZ3/05187 to P.P.-B.; DEC2011/01/B/NZ3/02145 and DEC-2013/10/E/NZ3/00673 to K.P. The Skorski's lab was supported by NIH(NCI) CA 134458 grant. K.P. is an ISAC Scholar Fellow 2012-2016.

\section{REFERENCES}

1. Kubota $\mathrm{T}$, Nagao $\mathrm{T}$, and Arimori $\mathrm{S}$. Bone marrow fibroblasts-conditioned medium regulates the proliferation of leukemic cells. Tokai J Exp Clin Med. 1988; 13:45-51.

2. Zhang B, Li M, McDonald T, Holyoake TL, Moon RT, Campana D, Shultz L, and Bhatia R. Microenvironmental protection of CML stem and progenitor cells from tyrosine kinase inhibitors through $\mathrm{N}$-cadherin and Wnt- $\beta$-catenin signaling. Blood. 2013; 121:1824-38.

3. Jin L, Tabe Y, Konoplev S, Xu Y, Leysath CE, Lu H, Kimura S, Ohsaka A, Rios M-B, Calvert L, Kantarjian H, Andreeff M, and Konopleva M. CXCR4 up-regulation by imatinib induces chronic myelogenous leukemia (CML) cell migration to bone marrow stroma and promotes survival of quiescent CML cells. Mol Cancer Ther. 2008; $7: 48-58$.
4. Zhang B, Ho YW, Huang Q, Maeda T, Lin A, Lee S-U, Hair A, Holyoake TL, Huettner C, and Bhatia R. Altered microenvironmental regulation of leukemic and normal stem cells in chronic myelogenous leukemia. Cancer Cell. 2012; 21:577-92.

5. Holtz MS, Forman SJ, and Bhatia R. Nonproliferating CML CD34+ progenitors are resistant to apoptosis induced by a wide range of proapoptotic stimuli. Leukemia. 2005; 19:1034-41.

6. Blazsek I, Farabos C, Quittet P, Labat ML, Bringuier AF, Triana BK, Machover D, Reynes M, and Misset JL. Bone marrow stromal cell defects and 1 alpha,25dihydroxyvitamin D3 deficiency underlying human myeloid leukemias. Cancer Detect Prev. 1996; 20:31-42.

7. Sawyers CL, Denny CT, and Witte ON. Leukemia and the disruption of normal hematopoiesis. Cell. 1991; 64:337-50.

8. Korkolopoulou P, Viniou N, Kavantzas N, Patsouris E, Thymara I, Pavlopoulos PM, Terpos E, Stamatopoulos K, Plata E, Anargyrou K, Androulaki A, Davaris P, and Yataganas X. Clinicopathologic correlations of bone marrow angiogenesis in chronic myeloid leukemia: a morphometric study. Leukemia. 2003; 17:89-97.

9. Kvasnicka HM, Thiele J, Staib P, Schmitt-Graeff A, Griesshammer M, Klose J, Engels K, and Kriener S. Reversal of bone marrow angiogenesis in chronic myeloid leukemia following imatinib mesylate (STI571) therapy. Blood. 2004; 103:3549-51.

10. Liu Y, Zhu X, Zeng C, Wu P, Wang H, Chen Z, and Li Q. Microvesicles secreted from human multiple myeloma cells promote angiogenesis. Acta Pharmacol Sin. 2014; $35: 230-8$.

11. Taverna S, Amodeo V, Saieva L, Russo A, Giallombardo M, De Leo G, and Alessandro R. Exosomal shuttling of miR126 in endothelial cells modulates adhesive and migratory abilities of chronic myelogenous leukemia cells. Mol Cancer. 2014; 13:169.

12. Hantschel O, Gstoettenbauer A, Colinge J, Kaupe I, Bilban M, Burkard TR, Valent P, and Superti-Furga G. The chemokine interleukin-8 and the surface activation protein CD69 are markers for Bcr-Abl activity in chronic myeloid leukemia. Mol Oncol. 2008; 2:272-81.

13. Zhu X, Wang L, Zhang B, Li J, Dou X, and Zhao RC. TGFbeta1-induced PI3K/Akt/NF-kappaB/MMP9 signalling pathway is activated in Philadelphia chromosome-positive chronic myeloid leukaemia hemangioblasts. J Biochem (Tokyo). 2011; 149:405-14.

14. Nieborowska-Skorska M, Hoser G, Rink L, Malecki M, Kossev P, Wasik MA, and Skorski T.Id1 Transcription Inhibitor-Matrix Metalloproteinase 9 Axis Enhances Invasiveness of the Breakpoint Cluster Region/Abelson Tyrosine Kinase-Transformed Leukemia Cells. Cancer Res. 2006; 66:4108-16.

15. Ries C, Loher F, Zang C, Ismair MG, and Petrides PE. Matrix Metalloproteinase Production by Bone Marrow 
Mononuclear Cells from Normal Individuals and Patients with Acute and Chronic Myeloid Leukemia or Myelodysplastic Syndromes. Clin Cancer Res. 1999; 5:1115-24.

16. Redondo-Muñoz J, Escobar-Díaz E, Samaniego R, Terol MJ, García-Marco JA, and García-Pardo A. MMP-9 in B-cell chronic lymphocytic leukemia is up-regulated by alpha4beta1 integrin or CXCR4 engagement via distinct signaling pathways, localizes to podosomes, and is involved in cell invasion and migration. Blood. 2006; 108:3143-51.

17. Lynch CC, and McDonnell S. The role of matrilysin (MMP7) in leukaemia cell invasion. Clin Exp Metastasis. 2000; 18:401-6.

18. Marquez-Curtis LA, Shirvaikar N, Turner AR, Mirza I, Surmawala A, Larratt LM, and Janowska-Wieczorek A. Membrane Type-1 Matrix Metalloproteinase Expression in Acute Myeloid Leukemia and Its Upregulation by Tumor Necrosis Factor- $\alpha$. Cancers. 2012; 4:743-62.

19. Wang M, and Kaufman RJ. The impact of the endoplasmic reticulum protein-folding environment on cancer development. Nat Rev Cancer. 2014; 14:581-97.

20. Vattem KM, and Wek RC. Reinitiation involving upstream ORFs regulates ATF4 mRNA translation in mammalian cells. Proc Natl Acad Sci U S A. 2004; 101:11269-74.

21. Piwocka K, Vejda S, Cotter TG, O’Sullivan GC, and McKenna SL. Bcr-Abl reduces endoplasmic reticulum releasable calcium levels by a Bcl-2-independent mechanism and inhibits calcium-dependent apoptotic signaling. Blood. 2006; 107:4003-10.

22. Kusio-Kobialka M, Podszywalow-Bartnicka P, Peidis P, Glodkowska-Mrowka E, Wolanin K, Leszak G, Seferynska I, Stoklosa T, Koromilas AE, and Piwocka K. The PERKeIF2 $\alpha$ phosphorylation arm is a pro-survival pathway of BCR-ABL signaling and confers resistance to imatinib treatment in chronic myeloid leukemia cells. Cell Cycle Georget Tex. 2012; 11:4069-78.

23. Podszywalow-Bartnicka P, Wolczyk M, Kusio-Kobialka M, Wolanin K, Skowronek K, Nieborowska-Skorska M, Dasgupta Y, Skorski T, and Piwocka K. Downregulation of BRCA1 protein in BCR-ABL1 leukemia cells depends on stress-triggered TIAR-mediated suppression of translation. Cell Cycle Georget Tex. 2014; 13:3727-41.

24. Zucal C, D'Agostino VG, Casini A, Mantelli B, Thongon N, Soncini D, Caffa I, Cea M, Ballestrero A, Quattrone A, Indraccolo S, Nencioni A, and Provenzani A. EIF2Adependent translational arrest protects leukemia cells from the energetic stress induced by NAMPT inhibition. BMC Cancer. 2015; 15:855.

25. Jiang L, Zang D, Yi S, Li X, Yang C, Dong X, Zhao C, Lan X, Chen X, Liu S, Liu N, Huang H, Shi X, Wang X, and Liu J. A microRNA-mediated decrease in eukaryotic initiation factor $2 \alpha$ promotes cell survival during PS-341 treatment. Sci Rep. 2016; 6:21565.
26. Klieser E, Illig R, Státtner S, Primavesi F, Jáger $\mathrm{T}$, Swierczynski S, Kiesslich T, Kemmerling R, Bollmann C, Di Fazio P, and Neureiter D. Endoplasmic Reticulum Stress in Pancreatic Neuroendocrine Tumors is Linked to Clinicopathological Parameters and Possible Epigenetic Regulations. Anticancer Res. 2015; 35:6127-36.

27. Palam LR, Gore J, Craven KE, Wilson JL, and Korc M. Integrated stress response is critical for gemcitabine resistance in pancreatic ductal adenocarcinoma. Cell Death Dis. 2015; 6:e1913.

28. Saveljeva S, Cleary P, Mnich K, Ayo A, Pakos-Zebrucka K, Patterson JB, Logue SE, and Samali A. Endoplasmic reticulum stress-mediated induction of SESTRIN 2 potentiates cell survival. Oncotarget. 2016; 7:12254-66. doi: 10.18632/oncotarget.7601.

29. Frassanito MA, Rao L, Moschetta M, Ria R, Di Marzo L, De Luisi A, Racanelli V, Catacchio I, Berardi S, Basile A, Menu E, Ruggieri S, Nico B, Ribatti D, Fumarulo R, Dammacco F, Vanderkerken K, and Vacca A. Bone marrow fibroblasts parallel multiple myeloma progression in patients and mice: in vitro and in vivo studies. Leukemia. 2014; 28:904-16.

30. Janel A, Dubois-Galopin F, Bourgne C, Berger J, Tarte K, Boiret-Dupré N, Boisgard S, Verrelle P, Déchelotte $\mathrm{P}$, Tournilhac $\mathrm{O}$, and Berger $\mathrm{M}$ G. The chronic lymphocytic leukemia clone disrupts the bone marrow microenvironment. Stem Cells Dev. 2014; 23:2972-82.

31. Roecklein BA, and Torok-Storb B. Functionally distinct human marrow stromal cell lines immortalized by transduction with the human papilloma virus E6/E7 genes. Blood. 1995; 85:997-1005.

32. Lu PD, Harding HP, and Ron D. Translation reinitiation at alternative open reading frames regulates gene expression in an integrated stress response. J Cell Biol. 2004; 167:27-33.

33. Krystkowiak I, Lenart J, Debski K, Kuterba P, Petas M, Kaminska B, and Dabrowski M. Nencki Genomics Database--Ensembl funcgen enhanced with intersections, user data and genome-wide TFBS motifs. Database J Biol Databases Curation. 2013; 2013:bat069.

34. Feng Y-X, Sokol ES, Del Vecchio CA, Sanduja S, Claessen JHL, Proia TA, Jin DX, Reinhardt F, Ploegh HL, Wang Q, and Gupta PB. Epithelial-to-mesenchymal transition activates PERK-eIF2 $\alpha$ and sensitizes cells to endoplasmic reticulum stress. Cancer Discov. 2014; 4:702-15.

35. Albrengues J, Bourget I, Pons C, Butet V, Hofman P, Tartare-Deckert S, Feral CC, Meneguzzi G, and Gaggioli C. LIF mediates proinvasive activation of stromal fibroblasts in cancer. Cell Rep. 2014; 7:1664-78.

36. Paggetti J, Haderk F, Seiffert M, Janji B, Distler U, Ammerlaan W, Kim YJ, Adam J, Lichter P, Solary E, Berchem G, and Moussay E. Exosomes released by chronic lymphocytic leukemia cells induce the transition of stromal cells into cancer-associated fibroblasts. Blood. 2015; 126:1106-17. 
37. Olsen CJ, Moreira J, Lukanidin EM, and Ambartsumian NS. Human mammary fibroblasts stimulate invasion of breast cancer cells in a three-dimensional culture and increase stroma development in mouse xenografts. BMC Cancer. 2010; 10:444.

38. Yamaguchi H, Yoshida N, Takanashi M, Ito Y, Fukami K, Yanagihara K, Yashiro M, and Sakai R. Stromal Fibroblasts Mediate Extracellular Matrix Remodeling and Invasion of Scirrhous Gastric Carcinoma Cells. PLoS ONE. 2014; 9:e85485.

39. Bejarano PA, Noelken ME, Suzuki K, Hudson BG, and Nagase H. Degradation of basement membranes by human matrix metalloproteinase 3 (stromelysin). Biochem J. 1988; 256:413-9.

40. Johnson JL, Dwivedi A, Somerville M, George SJ, and Newby AC. Matrix Metalloproteinase (MMP)-3 Activates MMP-9 Mediated Vascular Smooth Muscle Cell Migration and Neointima Formation in Mice. Arterioscler Thromb Vasc Biol. 2011; 31:e35-44.

41. Imai K, Yokohama Y, Nakanishi I, Ohuchi E, Fujii Y, Nakai N, and Okada Y. Matrix Metalloproteinase 7 (Matrilysin) from Human Rectal Carcinoma Cells activation of the precursor, interaction with other matrix metalloproteinases and enzymic properties. J Biol Chem. 1995; 270:6691-7.

42. Navratilova Z, Zatloukal J, Kriegova E, Kolek V, and Petrek M. Simultaneous up-regulation of matrix metalloproteinases $1,2,3,7,8,9$ and tissue inhibitors of metalloproteinases 1 , 4 in serum of patients with chronic obstructive pulmonary disease. Respirol Carlton Vic. 2012; 17:1006-12.

43. Pantanowitz L, Dezube BJ, Hernandez-Barrantes S, Tahan $\mathrm{SR}$, and Dabbous MK. Matrix metalloproteinases in the progression and regression of Kaposi's sarcoma. J Cutan Pathol. 2006; 33:793-8.

44. Gencer S, Cebeci A, and Irmak-Yazicioglu MB. Matrix metalloproteinase gene expressions might be oxidative stress targets in gastric cancer cell lines. Chin J Cancer Res Chung-Kuo Yen Cheng Yen Chiu. 2013; 25:322-33.

45. Gocheva V, Wang H-W, Gadea BB, Shree T, Hunter KE, Garfall AL, Berman T, and Joyce JA. IL-4 induces cathepsin protease activity in tumor-associated macrophages to promote cancer growth and invasion. Genes Dev. 2010; 24:241-55.

46. Kuester D, Lippert H, Roessner A, and Krueger S. The cathepsin family and their role in colorectal cancer. Pathol Res Pract. 2008; 204:491-500.

47. Kozlowski L, Wojtukiewicz MZ, and Ostrowska H. Cathepsin A activity in primary and metastatic human melanocytic tumors. Arch Dermatol Res. 2000; 292:68-71.

48. Krueger S, Kalinski T, Hundertmark T, Wex T, Küster D, Peitz U, Ebert M, Nägler DK, Kellner U, Malfertheiner P, Naumann M, Röcken C, and Roessner A. Up-regulation of cathepsin $\mathrm{X}$ in Helicobacter pylori gastritis and gastric cancer. J Pathol. 2005; 207:32-42.
49. Kolwijck E, Massuger LFAG, Thomas CMG, Span PN, Krasovec M, Kos J, and Sweep FCGJ. Cathepsins B, L and cystatin C in cyst fluid of ovarian tumors. J Cancer Res Clin Oncol. 2010; 136:771-8.

50. Zhang Z, Zhang H, Peng T, Li D, and Xu J. Melittin suppresses cathepsin $\mathrm{S}$-induced invasion and angiogenesis via blocking of the VEGF-A/VEGFR-2/MEK1/ERK1/2 pathway in human hepatocellular carcinoma. Oncol Lett. 2016 ; $11: 610-8$.

51. Ameri K, Luong R, Zhang H, Powell AA, Montgomery KD, Espinosa I, Bouley DM, Harris AL, and Jeffrey SS. Circulating tumour cells demonstrate an altered response to hypoxia and an aggressive phenotype. Br J Cancer. 2010; 102:561-9.

52. Nagelkerke A, Bussink J, Mujcic H, Wouters BG, Lehmann S, Sweep FCGJ, and Span PN. Hypoxia stimulates migration of breast cancer cells via the PERK/ATF4/ LAMP3-arm of the unfolded protein response. Breast Cancer Res BCR. 2013; 15:R2.

53. Zeng H, Zhang J-M, Du Y, Wang J, Ren Y, Li M, Li H, Cai Z, Chu Q, and Yang C. Crosstalk between ATF4 and MTA1/ HDAC1 promotes osteosarcoma progression. Oncotarget. 2016; 7:7329-42. doi: 10.18632/oncotarget.6940.

54. Dey S, Sayers CM, Verginadis II, Lehman SL, Cheng Y, Cerniglia GJ, Tuttle SW, Feldman MD, Zhang PJL, Fuchs SY, Diehl JA, and Koumenis C. ATF4-dependent induction of heme oxygenase 1 prevents anoikis and promotes metastasis. J Clin Invest. 2015; 125:2592-608.

55. Zhu H, Chen X, Chen B, Chen B, Song W, Sun D, and Zhao Y. Activating Transcription Factor 4 Promotes Esophageal Squamous Cell Carcinoma Invasion and Metastasis in Mice and Is Associated with Poor Prognosis in Human Patients. PLOS ONE. 2014; 9:e103882.

56. Axten JM, Romeril SP, Shu A, Ralph J, Medina JR, Feng Y, Li WH, Grant SW, Heerding DA, Minthorn E, Mencken T, Gaul N, Goetz A, Stanley T, Hassell AM, Gampe RT, Atkins C, Kumar R. Discovery of GSK2656157: An Optimized PERK Inhibitor Selected for Preclinical Development. ACS Med Chem Lett. 2013, 4:964-68.

57. Atkins C, Liu Q, Minthorn E, Zhang SY, Figueroa DJ, Moss K, Stanley TB, Sanders B, Goetz A, Gaul N, Choudhry AE, Alsaid H, Jucker BM, Axten JM, Kumar R. Characterization of a novel PERK kinase inhibitor with antitumor and antiangiogenic activity. Cancer Res. 2013; 73:1993-2002.

58. Rajesh K, Papadakis AI, Kazimierczak U, Peidis P, Wang S, Ferbeyre G, Kaufman RJ, and Koromilas AE. eIF2 $\alpha$ phosphorylation bypasses premature senescence caused by oxidative stress and pro-oxidant antitumor therapies. Aging (Albany NY). 2013; 5:884-901. doi: 10.18632/aging.100620.

59. Ong S-E, Blagoev B, Kratchmarova I, Kristensen DB, Steen H, Pandey A, and Mann M. Stable isotope labeling by amino acids in cell culture, SILAC, as a simple and accurate approach to expression proteomics. Mol Cell Proteomics. 2002; 1:376-86. 
60. Wiśniewski JR, Zougman A, Nagaraj N, and Mann M. Universal sample preparation method for proteome analysis. Nat Methods. 2009; 6:359-62.

61. Krijgsveld J, Gauci S, Dormeyer W, and Heck AJR. In-gel isoelectric focusing of peptides as a tool for improved protein identification. J Proteome Res. 2006; 5:1721-30.

62. Cox J, and Mann M. MaxQuant enables high peptide identification rates, individualized p.p.b.-range mass accuracies and proteome-wide protein quantification. Nat Biotechnol. 2008; 26:1367-72.
63. Cmoch A, Podszywalow-Bartnicka P, Palczewska M, Piwocka K, Groves P, and Pikula S. Stimulators of mineralization limit the invasive phenotype of human osteosarcoma cells by a mechanism involving impaired invadopodia formation. PloS One. 2014; 9:e109938.

64. Livak KJ, and Schmittgen TD. Analysis of relative gene expression data using real-time quantitative PCR and the 2(-Delta Delta C(T)) Method. Methods San Diego Calif. $2001 ; 25: 402-8$. 